Case Report

\title{
Efficacy of Tocilizumab in Limbic Encephalitis with Anti-CASPR2 Antibodies
}

\author{
Maurizio Benucci $\left(\mathbb{D},{ }^{1}\right.$ Luciana Tramacere, ${ }^{2}$ Maria Infantino $\mathbb{D}^{\mathbb{D}},{ }^{3}$ Mariangela Manfredi, ${ }^{3}$ \\ Valentina Grossi, ${ }^{3}$ Arianna Damiani, ${ }^{1}$ Francesca Li Gobbi, ${ }^{1}$ Maristella Piccininni, ${ }^{2}$ \\ Gaetano Zaccara, ${ }^{2}$ and Massimo Cincotta ${ }^{2}$ \\ ${ }^{1}$ Rheumatology Unit, S. Giovanni di Dio Hospital, Florence, Italy \\ ${ }^{2}$ Neurology Unit, S. Giovanni di Dio Hospital, Florence, Italy \\ ${ }^{3}$ Immunology and Allergology Laboratory, S. Giovanni di Dio Hospital, Florence, Italy
}

Correspondence should be addressed to Maurizio Benucci; maubenucci@tiscali.it

Received 24 October 2019; Revised 16 January 2020; Accepted 20 January 2020; Published 14 February 2020

Academic Editor: Isabella Laura Simone

Copyright ( 12020 Maurizio Benucci et al. This is an open access article distributed under the Creative Commons Attribution License, which permits unrestricted use, distribution, and reproduction in any medium, provided the original work is properly cited.

We report the case of a 64-year-old man who presented with subacute memory, balance impairment, behavioral and mood changes, and epileptic seizures. Magnetic resonance imaging (MRI) showed bilateral hippocampal abnormalities. Brain $\left[{ }^{18} \mathrm{~F}\right]-\mathrm{FDG}$ fluorodeoxyglucose positron emission tomography (PET) revealed hypometabolism in both the temporal lobe as well as in the left insular and parietal regions. The clinical and neuroradiological picture and the detection of anti-CASPR2 antibodies in serum oriented the diagnosis towards autoimmune limbic encephalitis. Intravenous high-dose steroid and immunoglobulin treatments were ineffective. We did not use rituximab for the presence of antibodies to HbcAg positivity. Tocilizumab given intravenously $8 \mathrm{mg} / \mathrm{kg}$ once a month for six months and then subcutaneously $162 \mathrm{mg}$ every week for six months resulted in clinical and neuroradiological improvement. These data support the efficacy of tocilizumab in autoimmune limbic encephalitis associated with anti-CASPR2 antibodies, which has been sporadically reported in the literature.

\section{Introduction}

Autoimmune etiology is increasingly recognized as a major cause of encephalitis [1-3]. The spectrum of autoimmune encephalitis (AE) is rapidly expanding with the continuous discovery of novel auto-antibodies [4]. Moreover, in other patients, clinical and magnetic resonance imaging (MRI) findings support the diagnosis of probable AE without demonstrated auto-antibody [5]. In a subset of patients, the outcomes following immunotherapies are good, regardless of the identification of auto-antibodies $[6,7]$. For patients nonresponsive to first-line immunotherapy such as steroids and IVIg, second-line immunotherapies such as rituximab, which induces CD20+ B-cell destruction, may yield substantial benefit [8]. Tocilizumab is a humanized anti-interleukin (IL)-6 receptor monoclonal antibody, which blocks IL-6-mediated signal transduction [9]. Owing to the crucial role of IL- 6 in stimulating both B and T cells in autoimmune processes [10-12], tocilizumab was established as efficient in various autoimmune diseases, including rheumatoid arthritis and systemic lupus erythematosus [13, 14]. Among the autoimmune central nervous system (CNS) disorders, a recent study reported a powerful disease modulation by tocilizumab in rituximab-refractory neuromyelitis optica (NMO) [15]. Regarding AE, successful treatment by tocilizumab was reported in several patients $[16,17]$, but in only one of these cases, contactin-associated protein-like 2 (CASPR2) antibodies were detected [16].

\section{Case Report}

A 64-year-old man was admitted to the neurology ward because of a disorder starting four months earlier with a oneweek-long hypomanic episode. Subsequently, he had presented attention deficit, loss of recollection for recent events, and repetitive questioning, anxiety, loss of emotional 
control, balance disorder, and secondarily generalized seizures preceded by impaired language production.

The medical history consisted of hypertension, cervical spondylosis, and a previous, short episode of paroxysmal atrial fibrillation.

On admission, routine blood tests including erythrocyte sedimentation rate were normal. Also, blood serology for cytomegalovirus, herpes simplex 1 and 2, herpes zoster, human immunodeficiency (HIV) viruses, and Lyme disease were negative.

Anti-dsDNA antibodies, antiextractable nuclear antigens, antiphospholipid antibodies, and antineutrophil cytoplasmic antibodies were negative. Cerebrospinal fluid (CSF) examination showed slightly increased protein $(0.57 \mathrm{~g} / \mathrm{l})$ and normal cellular content, as well as unremarkable IgG index. CSF oligoclonal bands were absent. No neurotrophic viruses neither mycobacterium tuberculosis were identified by CSF polymerase chain reaction analysis. Testing for anticontactin-associated protein 2 (CASPR2) auto-antibodies performed by indirect immunofluorescence on transfected cells and controltransfected cells (EU 90) at a starting dilution of $1: 10$ detected IgG against CASPR2 in serum $(1: 1000)$ (Euroimmun, Lübeck, Germany). We also evaluated the determination of anti-NMDA glutamate receptor antibodies, antileucine-rich glioma-inactivated 1 (LGI1), and antibody panels for paraneoplastic neurological syndromes with negative results. Antibody assessment was not performed in the cerebrospinal fluid. MRI showed slight bilateral hippocampal swelling, and mild FLAIR hyperintensity $\left[{ }^{18} \mathrm{~F}\right]$ fluorodeoxyglucose positron emission tomography $\left(\left[{ }^{18} \mathrm{~F}\right]-\mathrm{FDG}\right.$ PET) showed glucose metabolic alterations in both temporal lobes, mainly involving the mesial regions and in the left insular and parietal regions (Figure 1). Chest and abdomen CT scan, testicular ecography, and search for tumoral markers were negative. Clinical, neuroradiological, and laboratory investigations oriented the diagnosis towards anti-CASPR2 antibody-associated autoimmune limbic encephalitis. At the initiation of first-line immunotherapy, functional status assessed using the modified Rankin Scale (mRS) score was 3. High-dose steroid therapy (i.v. methylprednisolone $1 \mathrm{~g}$ daily for 5 days) and administration of IVIg $2 \mathrm{~g} / \mathrm{kg}$ in 5 days were ineffective. Conversely, cognitive disturbances worsened and disinhibited behaviour appeared in spite of risperidone treatment. In addition, despite the intake of lacosamide $200 \mathrm{mg}$ daily and levetiracetam $2000 \mathrm{mg}$ daily, seizure frequency increased to 23 per month. We did not use rituximab for the presence of antibodies to $\mathrm{HbcAg}$ positivity (total $\mathrm{Hb}$ core positive) and anti-HBV antibodies $64.90 \mathrm{mU} / \mathrm{ml}$. The patient presented a negative QuantiFERON (ESAT-6-CFP10 CD4/ CD8). Flow cytometric analysis of lymphocyte profiles showed CD3+ 557 cells/mcl, CD4+ 386 cells/mcl, CD8+ 142 cells/mcl, CD56+ 111 cells/mcl, CD14HLADR +745 cells $/ \mathrm{mcl}, \mathrm{CD} 28+35.9$ cells $/ \mathrm{mc}, \mathrm{CD} 28-0.5$ cells $/ \mathrm{mcl}$, CD19+ 184 cells/mcl, CD20+ 169 cells $/ \mathrm{mcl}, \mathrm{CD} 38+8.4$ cells/mcl, CD27+ naive 133 cells $/ \mathrm{mcl}$, and CD27+ memory 2 cells $/ \mathrm{mcl}$. The value of the circulating interleukin (IL)-6 was $23.9 \mathrm{pg} / \mathrm{mL}$ (human IL-6 instant enzyme-linked immunosorbent assay, eBioscience, Bender MedSystem GmbH, Vienna, Austria; normal value $<3 \mathrm{pg} / \mathrm{mL}$ ). We started tocilizumab $8 \mathrm{mg} / \mathrm{kg}$ once a month for six months i.v. and then $162 \mathrm{mg}$ every week sc. This treatment determined cognitive, balance, and a significant improvement in metabolic uptake at $[18 \mathrm{~F}]$ fluorodeoxyglucose positron emission tomography ([18F]-FDG PET) (Figure 2). Findings of formal neuropsychological assessment before and after one month of tocilizumab treatment are shown in Table 1. Moreover, behavioral changes and seizures subsided. Also, the titer of antiCASPR2 antibodies was also reduced to $1: 100$. After 4 months of therapy, functional status assessed using the $\mathrm{mRS}$ score was 0 , and the patient was able to resume his work.

\section{Discussion}

In recent years, case reports and clinical series have been published in the use of tocilizumab in AE [17, 18]. Ninetyone patients with inadequate clinical response to first-line immunotherapy and following rituximab were retrospectively reviewed. Thirty (33.0\%) patients were included in the tocilizumab group, $31(34.0 \%)$ in the additional rituximab group, and $30(33.0 \%)$ in the observation group. The tocilizumab group showed more frequent favorable mRS scores at 2 months from treatment initiation and at the last followup compared with those at the relevant time points of the remaining groups. The majority $(89.5 \%)$ of the patients with clinical improvement at 1 month from tocilizumab treatment maintained a long-term favorable clinical response [17]. According to the auto-antibody tests of the patients' serum/CSF, 26 (28.6\%) patients had anti-NMDA-R antibodies, 3 (3.3\%) had antileucine-rich glioma-inactivated 1 antibodies, and $2(2.2 \%)$ had antiamphiphysin antibodies. The remaining $60(65.9 \%)$ patients showed negative results on the auto-antibody detection test, and no patient had antiCASPR2 antibodies [17]. In another clinical series on 3 cases, tocilizumab has also been used successfully in pediatric forms [19]. Therefore, the drug was included as a third line of treatment even in the encephalitis forms of children [20]. Based on the review of the literature, this is the second case of autoimmune encephalitis with antipositive CASPR2 treated with tocilizumab [16]. In our patient, the therapy resulted in a titer reduction of anti-CASPR2 antibodies although this does not seem to correlate according to some reports with the prognostic trend [21]. The presence of CASPR2 antibodies is associated with a subgroup of autoimmune-mediated neurological disorders, including limbic encephalitis, neuromyotonia, and Morvan syndrome [22]. A previous study has revealed the efficacy of tocilizumab in rituximab-refractory NMO spectrum disorders [15]. The efficacy of tocilizumab can be explained by the extensive pathophysiologic mechanisms by which IL-6 induces and enhances autoimmunity [23, 24]. IL-6 not only induces B-cell differentiation and proliferation but also promotes the differentiation of a main inducer of autoimmune tissue damage, IL-17-producing T-helper cells, from naive T cells 

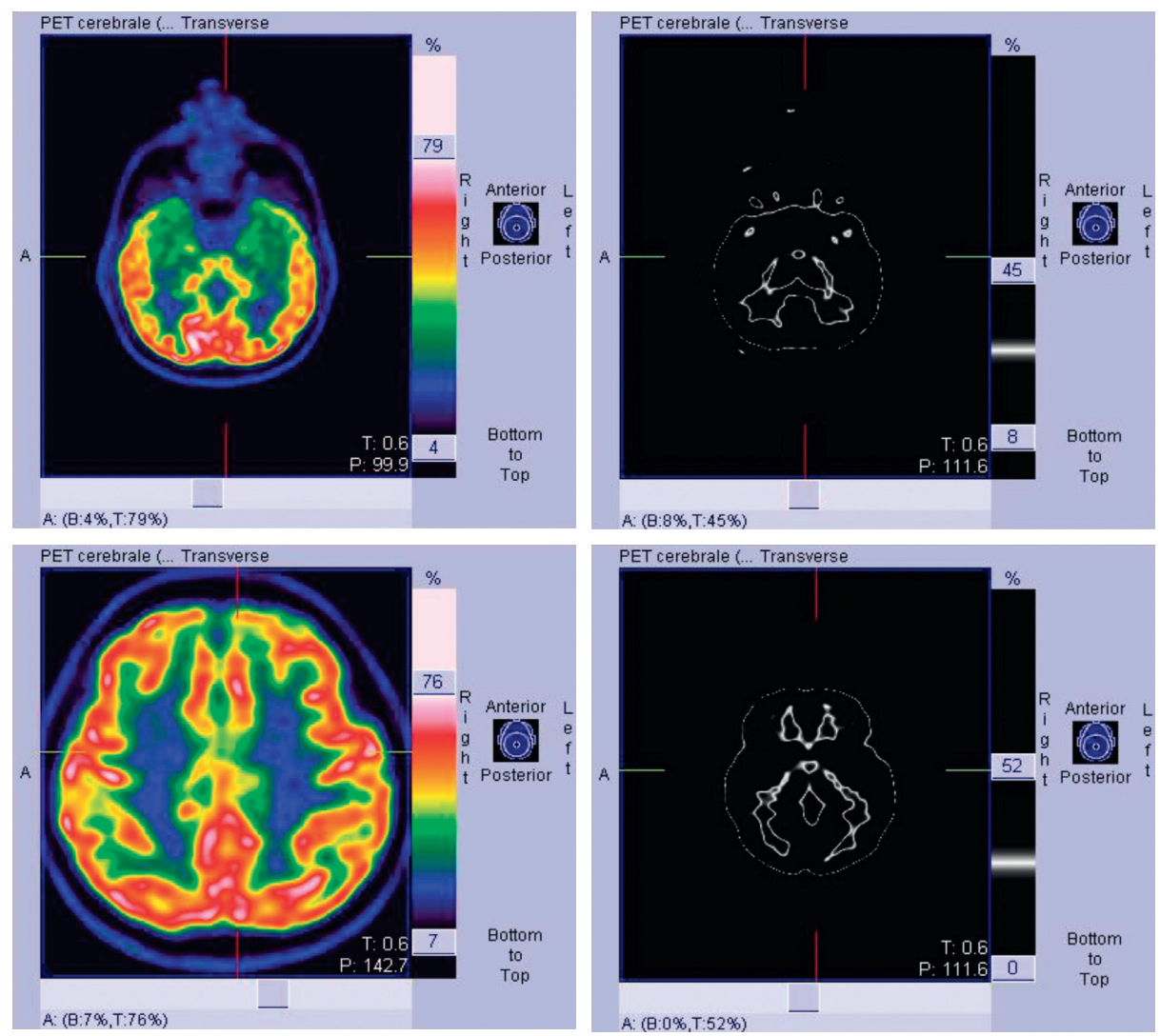

(a)
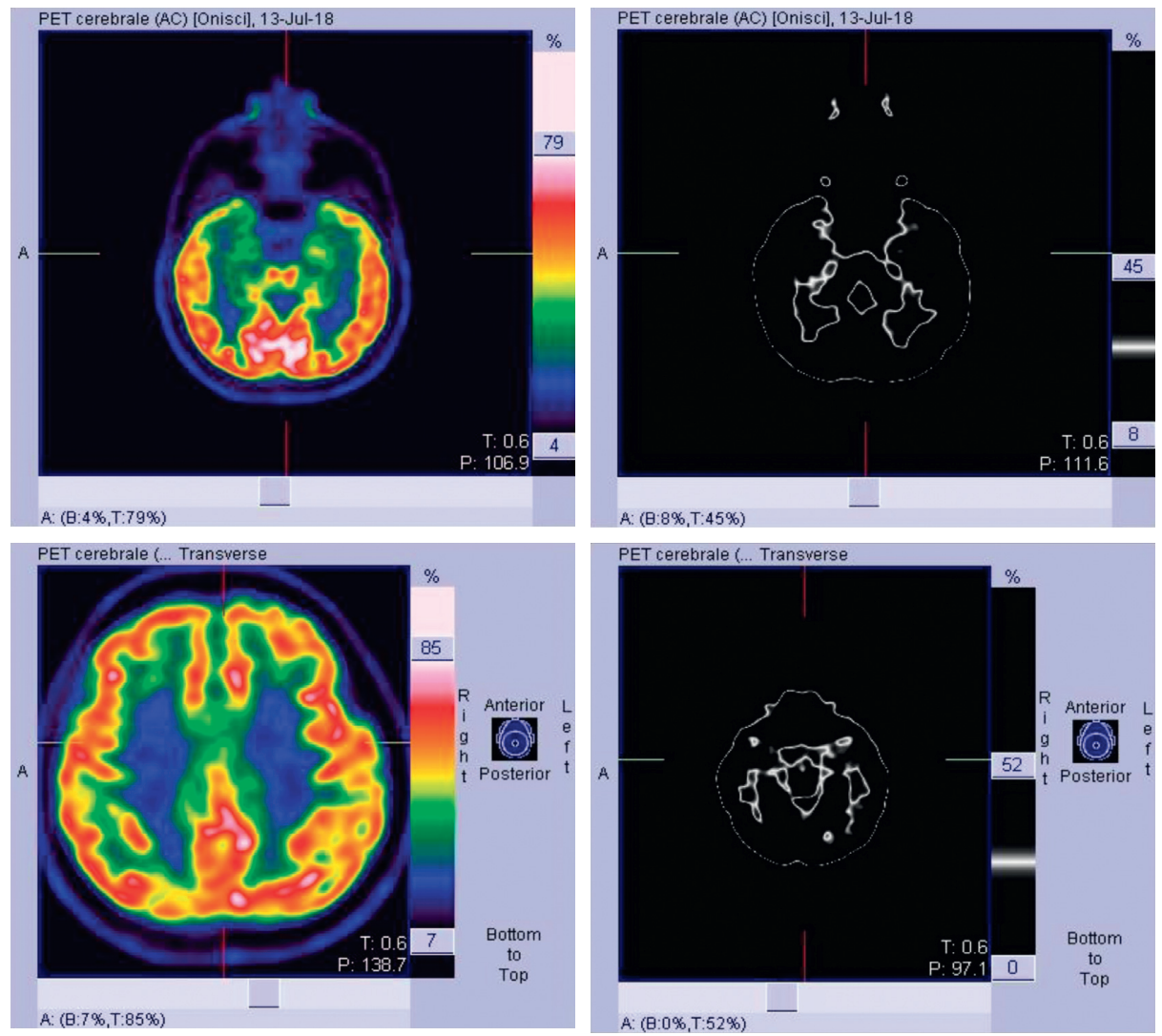

(b)

FigURE 1: $\left[{ }^{18} \mathrm{~F}\right]$ fluorodeoxyglucose positron emission tomography $\left(\left[{ }^{18} \mathrm{~F}\right]\right.$-FDG PET) showed glucose metabolic alterations in both temporal lobes, mainly involving the mesial regions, and in the left insular and parietal regions. 

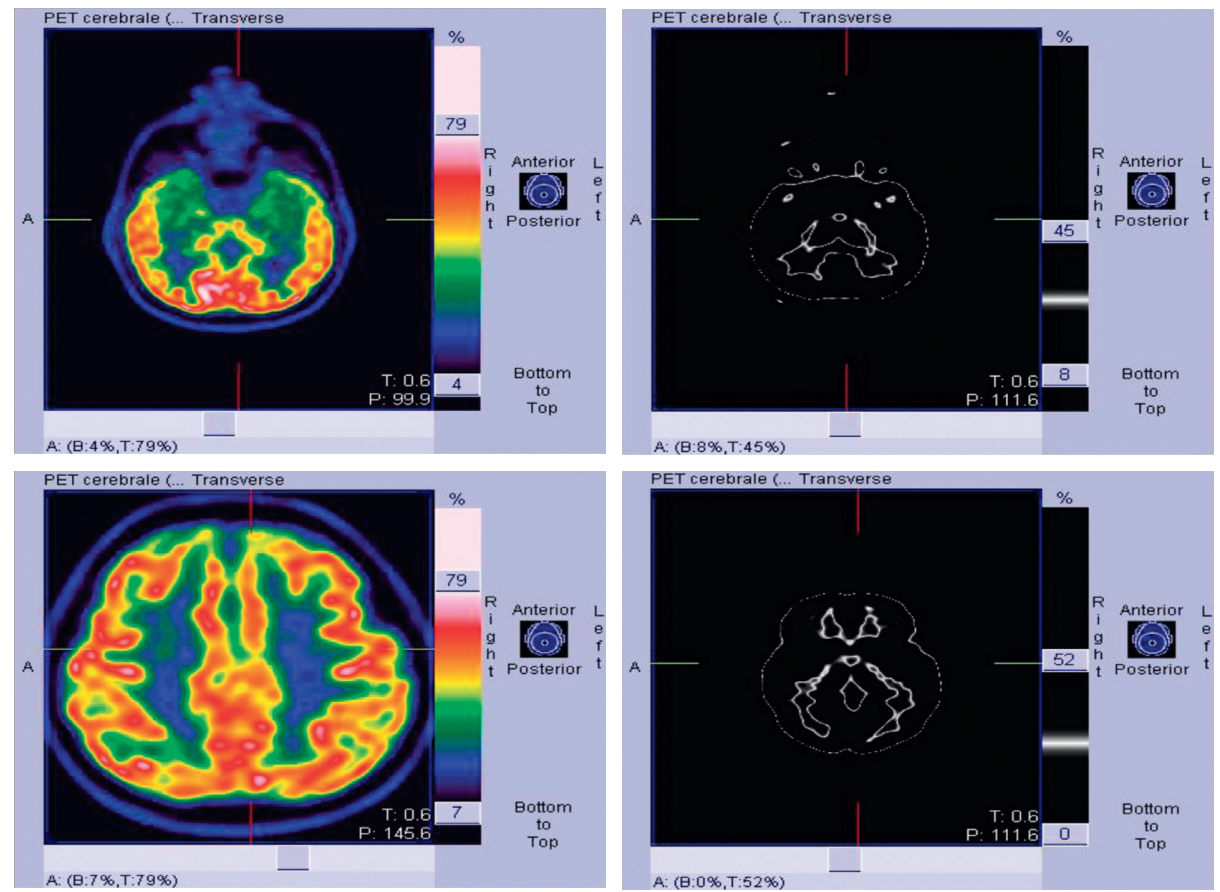

(a)
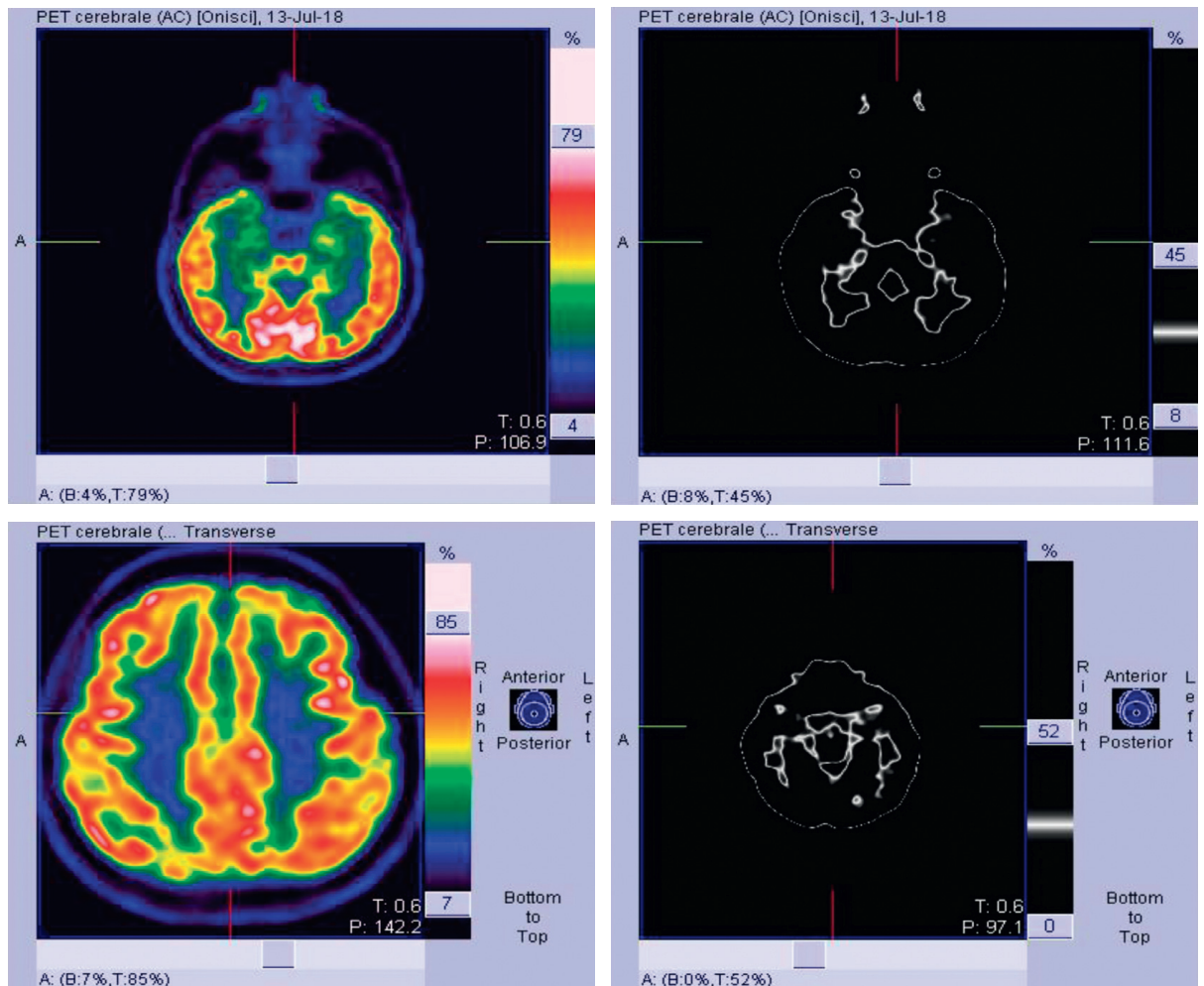

(b)

FIGURE 2: A significant improvement in metabolic uptake at [18F] fluorodeoxyglucose positron emission tomography ([18F]-FDG PET).

[24]. IL-6 inhibits regulatory T-cell differentiation, which is crucial in maintaining the balance against IL-17-producing T-helper cells in regulating autoimmune processes. Furthermore, IL-6 stimulates the differentiation of CD8+ cytotoxic $\mathrm{T}$ cells, which promote excitotoxicity-induced neuronal damage [25]. Recently, the safety of tocilizumab has also been observed in demyelinating pathologies and CNS complications in rheumatoid arthritis [26].

Our clinical case confirms that tocilizumab can improve the cases of autoimmune encephalitis with anti-CASPR2 
TABLE 1: Evaluation of psychometric tests during tocilizumab treatment.

\begin{tabular}{lcc}
\hline Psychometric tests & $\begin{array}{c}\text { First evaluation } \\
\text { score }\end{array}$ & $\begin{array}{c}\text { Second evaluation } \\
\text { score }\end{array}$ \\
\hline $\begin{array}{l}\text { Rey auditory verbal } \\
\text { learning test }\end{array}$ & 0 & 2 \\
Babcock story recall test & 4 & 4 \\
$\begin{array}{l}\text { Semantic verbal fluency } \\
\text { test }\end{array}$ & 4 & 4 \\
Phonemic verbal fluency & 3 & 4 \\
test & 2 & 4 \\
Attentive matrices test & 0 & 2 \\
Trail making test & & \\
\hline
\end{tabular}

antibodies, and this therapeutic strategy can be reserved for patients resistant or intolerant to other first- or second-line immunosuppressive therapy.

\section{Conflicts of Interest}

The authors declare that they have no conflicts of interest.

\section{References}

[1] E. Lancaster, E. Martinez-Hernandez, and J. Dalmau, "Encephalitis and antibodies to synaptic and neuronal cell surface proteins," Neurology, vol. 77, no. 2, pp. 179-189, 2011.

[2] L. Zuliani, F. Graus, B. Giometto, C. Bien, and A. Vincent, "Central nervous system neuronal surface antibody associated syndromes: review and guidelines for recognition," Journal of Neurology, Neurosurgery \& Psychiatry, vol. 83, no. 6, pp. 638-645, 2012.

[3] M. S. Gable, H. Sheriff, J. Dalmau, D. H. Tilley, and C. A. Glaser, "The frequency of autoimmune N-methyl-Daspartate receptor encephalitis surpasses that of individual viral etiologies in young individuals enrolled in the California Encephalitis Project," Clinical Infectious Diseases, vol. 54, no. 7, pp. 899-904, 2012.

[4] T. Armangue, F. Leypoldt, and J. Dalmau, "Autoimmune encephalitis as differential diagnosis of infectious encephalitis," Current Opinion in Neurology, vol. 27, no. 3, pp. 361-368, 2014.

[5] F. Graus, M. J. Titulaer, R. Balu et al., "A clinical approach to diagnosis of autoimmune encephalitis," The Lancet Neurology, vol. 15, no. 4, pp. 391-404, 2016.

[6] T. D. Singh, J. E. Fugate, and A. A. Rabinstein, "The spectrum of acute encephalitis: causes, management, and predictors of outcome," Neurology, vol. 84, no. 4, pp. 359-366, 2015.

[7] Y. Hacohen, S. Wright, P. Waters et al., "Paediatric autoimmune encephalopathies: clinical features, laboratory investigations and outcomes in patients with or without antibodies to known central nervous system autoantigens," Journal of Neurology, Neurosurgery \& Psychiatry, vol. 84, no. 7, pp. 748-755, 2013.

[8] W.-J. Lee, S.-T. Lee, J.-I. Byun et al., "Rituximab treatment for autoimmune limbic encephalitis in an institutional cohort," Neurology, vol. 86, no. 18, pp. 1683-1691, 2016.

[9] T. Tanaka, M. Narazaki, and T. Kishimoto, "Anti-interleukin6 receptor antibody, tocilizumab, for the treatment of autoimmune diseases," FEBS Letters, vol. 585, no. 23, pp. 36993709, 2011.
[10] M. Okada, M. Kitahara, S. Kishimoto, T. Matsuda, T. Hirano, and T. Kishimoto, "IL-6/BSF-2 functions as a killer helper factor in the in vitro induction of cytotoxic T cells," Journal of Immunology, vol. 141, no. 5, pp. 1543-1549, 1988.

[11] A. Kimura and T. Kishimoto, "IL-6: regulator of treg/Th17 balance," European Journal of Immunology, vol. 40, no. 7, pp. 1830-1835, 2010.

[12] T. Kishimoto, "Interleukin-6: from basic science to medicine40 years in immunology," Annual Review of Immunology, vol. 23 , no. 1, pp. 1-21, 2005.

[13] N. Nishimoto, N. Miyasaka, K. Yamamoto, S. Kawai, T. Takeuchi, and J. Azuma, "Long-term safety and efficacy of tocilizumab, an anti-IL-6 receptor monoclonal antibody, in monotherapy, in patients with rheumatoid arthritis (the STREAM study): evidence of safety and efficacy in a 5-year extension study," Annals of the Rheumatic Diseases, vol. 68, no. 10, pp. 1580-1584, 2009.

[14] G. G. Illei, Y. Shirota, C. H. Yarboro et al., "Tocilizumab in systemic lupus erythematosus: data on safety, preliminary efficacy, and impact on circulating plasma cells from an openlabel phase I dosage-escalation study," Arthritis \& Rheumatism, vol. 62, no. 2, pp. 542-552, 2010.

[15] M. Ringelstein, I. Ayzenberg, J. Harmel et al., "Long-term Therapy with interleukin 6 receptor blockade in highly active neuromyelitis optica spectrum disorder," JAMA Neurology, vol. 72, no. 7, pp. 756-763, 2015.

[16] C. Krogias, R. Hoepner, A. Müller, C. Schneider-Gold, A. Schröder, and R. Gold, "Successful treatment of anti-Caspr2 syndrome by interleukin 6 receptor blockade through tocilizumab," JAMA Neurology, vol. 70, no. 8, pp. 1056-1059, 2013.

[17] W.-J. Lee, S.-T. Lee, J. Moon et al., “Tocilizumab in autoimmune encephalitis refractory to rituximab: an institutional cohort study," Neurotherapeutics, vol. 13, no. 4, pp. 824-832, 2016.

[18] Y. W. Shin, S. T. Lee, K. I. Park et al., "Treatment strategies for autoimmune encephalitis," Therapeutic Advances in Neurological Disorders, vol. 11, p. 175628561772234, 2017.

[19] R. L. Randell, A. V. Adams, and H. Van Mater, "Tocilizumab in refractory autoimmune encephalitis: a series of pediatric cases," Pediatric Neurology, vol. 86, pp. 66-68, 2018.

[20] C. Stingl, K. Cardinale, and H. Van Mater, "An update on the treatment of pediatric autoimmune encephalitis," Current Treatment Options in Rheumatology, vol. 4, no. 1, pp. 14-28, 2018.

[21] C. G. Bien, "Value of autoantibodies for prediction of treatment response in patients with autoimmune epilepsy: review of the literature and suggestions for clinical management," Epilepsia, vol. 54, no. Suppl 2, pp. 48-55, 2013.

[22] R. Singh, P. Das, U. Kaur et al., "Morvan's syndrome-is a pathogen behind the curtain?" Neurological Sciences, vol. 39, no. 11, pp. 1965-1969, 2018.

[23] T. Kishimoto, "IL-6: from its discovery to clinical applications," International Immunology, vol. 22, no. 5, pp. 347-352, 2010.

[24] K.-M. Chavele, E. Merry, and M. R. Ehrenstein, "Cutting edge: circulating plasmablasts induce the differentiation of human T follicular helper cells via IL-6 production," The Journal of Immunology, vol. 194, no. 6, pp. 2482-2485, 2015.

[25] M. Mihara, K. Kasutani, M. Okazaki et al., "Tocilizumab inhibits signal transduction mediated by both mIL-6R and sIL-6R, but not by the receptors of other members of IL-6 cytokine family," International Immunopharmacology, vol. 5, no. 12, pp. 1731-1740, 2005.

[26] F. Atzeni, R. Talotta, I. F. Masala, M. C. Gerardi, R. Casale, and P. Sarzi-Puttini, "Central nervous system involvement in rheumatoid arthritis patients and the potential implications of using biological agents," Best Practice \& Research Clinical Rheumatology, vol. 32, no. 4, pp. 500-510, 2018. 